\title{
Conhecimento e adesão às recomendações de biossegurança no Corpo de Bombeiros Militar de Minas Gerais
}

\author{
KNOWLEDGE AND ADHERENCE TO BIOSAFETY RECOMMENDATIONS IN A \\ MILITARY FIRE BRIGADE IN MINAS GERAIS
}

\section{CONOCIMIENTO Y ADHESIÓN A LAS RECOMENDACIONES DE BIOSEGURIDAD EN EL CUERPO MILITAR DE BOMBEROS DE MINAS GERAIS}

\section{Adriana Cristina Oliveira ${ }^{1}$, Bruno César Amorim Machado ${ }^{2}$, Camila Sarmento Gama ${ }^{3}$}

\section{RESUMO}

Objetivou-se com este trabalho avaliar o conhecimento e as atitudes de militares do Corpo de Bombeiros Militar de Belo Horizonte-MG acerca da adesão às recomendações de biossegurança. Trata-se de estudo transversal realizado no período de janeiro a fevereiro de 2011. Utilizou-se um questionário estruturado composto de perguntas sobre conhecimentos e atitudes relativos à biossegurança e fatores dificultadores do uso de equipamentos de proteção individual. Evidenciou-se conhecimento adequado dos profissionais sobre higienização das mãos $(90,4 \%)$ e precauções padrão (89\%); hábito de sempre usar luvas $(95,7 \%)$; desconhecimento da ação do álcool a $70 \%(77,5 \%)$ e citação do capote como o equipamento de proteção individual mais difícil de ser utilizado. Entretanto, a maioria desconhecia a condição sorológica para hepatite B (25\%). Conhecimentos e atitudes mostraram-se condizentes com as recomendações de biossegurança, mas há necessidade de enfatizar a importância de realizar o esquema vacinal para hepatite $B$.

\section{DESCRITORES}

Exposição a agentes biológicos

Assistência pré-hospitalar

Precauções universais

Saúde do trabalhador

\begin{abstract}
This study aimed to assess the knowledge and attitudes concerning adherence to biosafety recommendations of the military personnel of Belo Horizonte's Military Fire Brigade in Minas Gerais . A cross-sectional study was conducted from January to February 2011. A structured questionnaire was used, consisting of questions regarding knowledge and attitudes related to biosafety and the factors hindering the use of personal protective equipment. The results showed that the personnel had adequate knowledge of hand hygiene (90.4\%) and standard precautions (89\%), such as the habit of always wearing gloves (95.7\%), but lacked knowledge about the antiseptic activity of $70 \%$ alcohol (77.5\%). The cloak was mentioned as the piece of personal protective equipment that was most difficult to use. However, most of the personnel were unaware of their serological status for hepatitis B (25\%). Their knowledge and attitudes were consistent with the biosafety recommendations, but the importance of hepatitis $B$ immunization must be emphasized.
\end{abstract}

\section{DESCRIPTORS \\ Exposure to biological agents \\ Pre-hospital care \\ Universal precautions \\ Occupational health}

\begin{abstract}
RESUMEN
Se objetivó evaluar conocimientos y aptitudes de militares del Cuerpo Militar de Bomberos de Belo Horizonte-MG respecto de su adhesión a las recomendaciones de bioseguridad. Se realizó estudio transversal entre enero y febrero de 2012. Se utilizó cuestionario estructurado compuesto por preguntas sobre conocimientos y aptitudes relativas a bioseguridad y factores diversos del uso de equipamientos de protección individual. Se evidenció conocimiento adecuado de los profesionales sobre higienización de manos $(90,4 \%)$ y precauciones estándar (89\%), la costumbre de utilizar guantes habitualmente $(95,7 \%)$; desconocimiento de la acción del alcohol al $70 \%(77,5 \%)$ y citación del capote como el equipo de protección individual más difícil de utilizar. Mientras tanto, la mayoría desconocía la condición serológica para hepatitis B (25\%). Tanto conocimientos como aptitudes mostraron condecirse con las recomendaciones de bioseguridad, aunque existe la necesidad de enfatizar la importancia de realizar un esquema de vacunación contra la hepatitis B.
\end{abstract}

\section{DESCRIPTORES \\ Exposición a agentes biológicos \\ Atención prehospitalaria \\ Precauciones universales Salud laboral}

${ }^{1}$ Enfermeira. Pós-Doutora pela New York University, Estados Unidos. Professora Associada da Escola de Enfermagem da Universidade Federal de Minas Gerais. Líder do Núcleo de Estudos e Pesquisas em Infecção Relacionada ao Cuidar em Saúde/CNPq. Belo Horizonte, MG, Brasil. adrianacoliveira@gmail.com ${ }^{2}$ Enfermeiro pela Escola de Enfermagem da Universidade Federal de Minas Gerais. Oficial do Corpo de Bombeiro Militar de Minas Gerais. Belo Horizonte, MG, Brasil. brunochedidsports@yahoo.com.br ${ }^{3}$ Enfermeira. Mestranda em Enfermagem pelo Programa de Pós-Graduação da Escola de Enfermagem da Universidade Federal de Minas Gerais. Membro do Núcleo de Estudos e Pesquisas em Infecção Relacionada ao Cuidar em Saúde/CNPq. Belo Horizonte, MG, Brasil. camilasarmento@ig.com.br 


\section{INTRODUÇÃO}

$\mathrm{O}$ atendimento pré-hospitalar (APh), no Brasil, consiste no serviço prestado a vítimas clínicas ou traumáticas antes de sua chegada ao estabelecimento de saúde de referência mais próximo, podendo ser realizado por profissionais treinados, sejam médicos ou não ${ }^{(1)}$ e prestado por unidades fixas e móveis ${ }^{(2-3)}$.

$\mathrm{O}$ atendimento pré-hospitalar móvel objetiva atender precocemente a vítima após a ocorrência de um agravo a sua saúde de natureza clínica, cirúrgica, traumática e psiquiátrica, e que possa causar sofrimento, sequelas ou óbito. Requer atendimento e/ou transporte adequado a um serviço de saúde devidamente hierarquizado e integrado ao Sistema Único de Saúde.

$\mathrm{O}$ atendimento pré-hospitalar móvel pode ser primário, quando o pedido de socorro é realizado por um cidadão, ou secundário, quando solicitado pelo serviço de saúde no qual o paciente já tenha recebido o primeiro atendimento necessário à estabilização do quadro de urgência, necessitando ainda de ser conduzido a outro serviço de maior complexidade ${ }^{(4)}$.

Em Belo Horizonte, o atendimento pré-hospitalar é realizado pelo Serviço de Atendimento Móvel de Urgência (SAMU) ou pelo Corpo de Bombeiros Militar de Minas Gerais (CBMMG). Ambos possuem central de regulação de chamadas de acesso gratuito. $\mathrm{A}$ diferença entre ambos é que o primeiro possui profissionais com formação e atuação na área da saúde, como médico, enfermeiros e técnicos de enfermagem, ao passo que o segundo é integrado por bombeiros militares capacitados como socorristas em suporte básico de vida (SBV), porém sem formação técnica na área da saúde ${ }^{(2)}$.

Embora treinados, os socorristas do Corpo de Bombeiros Militar de Minas Gerais não estão habilitados a realizar procedimentos invasivos. Ainda assim, expõem-se com grande frequência a materiais biológicos no desempenho de suas atividades. A exposição ao material biológico representa um elevado risco ocupacional nesta categoria.

Acidentes ocupacio--nais relacionados a materiais biológicos em serviços de atendimento pré-hospitalar móvel podem acontecer por meio de contato direto com sangue, secreções, excreções e outros fluidos corpóreos, infectados ou não, ou por contato indireto, como transferência de patógenos por meio de materiais e equipamentos contaminados ${ }^{(5)}$.

A chance de acidente ocupacional no serviço de atendimento pré-hospitalar móvel aumenta em razão das seguintes características: o espaço é limitado dentro das viaturas, com ventilação restrita que dificulta a recirculação do ar; o movimento do tráfego proporciona trepidações, solavancos e propulsão dos corpos, pela energia cinética decorrente das acelerações ou desacelerações dos veículos, das curvas acentuadas e da alta velocidade ${ }^{(1)}$; e o atendimento de emergência prestado exige destreza, habilidade e agilidade, fatores desencadeadores de um elevado nível de estresse, favorecendo a ocorrência do acidente.

A fim de minimizar o contato com o material biológico e proteger os profissionais a eles expostos, o Centers for Disease Control and Prevention (CDC), editou, em 1966, nos Estados Unidos, o Guia de Precaução e Isolamento, com recomendações a serem adotadas no atendimento de todo e qualquer paciente, independente de seu diagnóstico, denominadas precauções-padrão. Essas foram mantidas e reforçadas na revisão do Guia, em 2007. Dentre as medidas preconizadas, incluem-se: higienização das mãos, uso de equipamento de proteção individual (EPI), vacinação contra a hepatite $B$ e descarte adequado de materiais pérfurocortantes ${ }^{(6)}$.

A falta adesão a medidas de precaução padrão pelos profissionais pode resultar em exposição a material biológico, aumentando a chance de contaminação por micro-organismos potencialmente causadores de infecções, o que, consequentemente, pode acarretar tanto ausências ao trabalho, temporárias ou permanentes, como licenças médicas e até mesmo casos de invalidez.

A adesão a essas medidas depende, todavia, da oferta e disponibilidade de EPI pela instituição, do conhecimento acerca de sua utilização por parte dos trabalhadores envolvidos no cuidado aos usuários em todos os níveis de atenção à saúde, inclusive no atendimento pré-hospitalar, do qual participam outros profissionais, como os militares.

Considerando as características do trabalhador do resgate do Corpo de Bombeiros Militar de Minas Gerais e a escassez de trabaIhos sobre a segurança e os riscos ocupacionais relacionados a sua exposição a material biológico, tornam-se de extrema relevância o conhecimento e a adesão desses profissionais às recomendações de biossegurança, a fim de aprimorar a gestão do conhecimento na instituição, valorizar a saúde do trabalhador e reduzir os riscos ocupacionais ${ }^{(5)}$.

Nesse sentido, o objetivo deste trabalho foi avaliar o conhecimento e as atitudes dos militares do Corpo de Bombeiros Militar de Minas Gerais lotados em Belo Horizonte acerca da adesão às recomendações de biossegurança.

\section{MÉTODO}

Realizou-se uma pesquisa de corte transversal e de abordagem quantitativa em onze unidades do Corpo de Bombeiros Militar de Minas Gerais do município de Belo Horizonte.
Conhecimento e adesão às recomendações de biossegurança no Corpo de Bombeiros Militar de Minas Gerais Oliveira AC, Machado BCA, Gama CS 
Os sujeitos desta pesquisa foram militares atuantes no Corpo de Bombeiros Militar de Minas Gerais do referido Município, os quais foram previamente convidados e esclarecidos quanto aos objetivos do estudo, tendo aceitado participar mediante a leitura e a assinatura do Termo de Consentimento Livre e Esclarecido (TCLE). Excluíram-se aqueles que se encontravam de férias, de folga ou no gozo de licença médica no período da coleta de dados. Após sua apresentação por um dos pesquisadores, o instrumento de coleta de dados foi respondido de forma individual pelos participantes na presença deste pesquisador.

Utilizou-se para o estudo um questionário anônimo, estruturado, autoaplicável e validado por especialistas na área de infecções relacionadas à assistência em saúde. $O$ teste-piloto foi realizado em amostragem semelhante a este grupo final. No questionário, abordaram-se aspectos referentes a: dados demográficos e questões sobre conhecimento e atitude quanto à adesão às recomendações de biossegurança, fatores intervenientes para a baixa ou não adesão ao uso dos EPI.

Após esta etapa, os dados obtidos foram digitados e analisados com o auxílio do software estatístico Statistical Package for the Social Sciences (SPSS ${ }^{\oplus}$ ) Versão13.0. Para o tratamento dos dados, realizou-se análise descritiva e univariada.

O projeto foi aprovado pelo Comitê de Ética em Pesquisa da Universidade Federal de Minas Gerais (Parecer ETIC 458/05) e aceito pelo Comando Operacional de Bombeiros (COB) 7262/09 - COB, responsável por todas as unidades operacionais do Estado de Minas Gerais.

\section{RESULTADOS}

De um total de 488 militares abordados no serviço operacional do Corpo de Bombeiros Militar de Minas Gerais de Belo Horizonte durante o período de coleta de dados, 409 (83,8\%) aceitaram participar do estudo; 67 $(13,7 \%)$ recusaram e $12(2,5 \%)$ não finalizaram o preenchimento do questionário, devido ao chamamento para atender a ocorrências no momento de sua aplicação sem previsão de retorno dos participantes.

Do total de profissionais que concordaram em participar do estudo, $6,8 \%$ eram mulheres; e $93,2 \%$ eram homens. A média de idade foi de 30,8 anos, com desvio padrão de 8,14.

No que se refere à experiência profissional no Corpo de Bombeiros Militar de Minas Gerais, 40,8\% dos entrevistados relataram tempo de serviço de um mês a dois anos completos; $22,7 \%$, entre dois e dez anos; e $35,7 \%$, mais de dez anos de serviço.

Os cursos realizados pelos participantes para ingressar na instituição foram: Curso de Formação de Soldados (CFSd)/ Curso Técnico em Segurança Pública (CTSP), para a formação de cabos ou soldados; Curso de Formação de Sargentos (CFS)/Curso Especial de Formação de Sargentos (CEFS)/Curso Intensivo de Formação de Sargentos (CIFS), para a formação de sargentos ou subtenentes; Curso de Aperfeiçoamento de Sargentos (CAS), para a formação o aperfeiçoamento de 20 Sargentos; e Curso de Formação de Oficiais (CFO)/Curso de Habilitação de Oficiais (CHO)/Curso Especial de Formação de Oficiais, para a formação de oficiais. Atualmente, os cursos de CTSP, CIFS e CEFO não têm sido mais ofertados.

Esses cursos possuem disciplinas/módulos que abordam, entre outros temas, Técnicas de primeiros socorros e Segurança do trabalhador. A média de duração de tempo dedicado aos cursos de formação ou aperfeiçoamento da corporação foi de 6,6 meses.

Ao serem questionados acerca do aprendizado, $72,9 \%$ afirmaram que receberam informações acerca dos temas Biossegurança ou Segurança da vítima, em alguma disciplina/módulo ou palestra durante os cursos de formação do corpo de bombeiros, sendo que para $28,6 \%$ este contato ocorreu nos dois anos anteriores à coleta de dados.

Tabela 1 - Distribuição dos profissionais do corpo de bombeiros militares, segundo a formação/capacitação técnico-científico Belo Horizonte, 2011.

\begin{tabular}{lcc}
\hline Variável & N (409) & \% \\
\hline Graduação em nível superior & & \\
Sim & 81 & 19,8 \\
Não & 327 & 80.0 \\
Não respondeu & 1 & 0,2 \\
\hline Curso realizado no CBMMG* & & \\
CFSd/ CTSP & 318 & 77,8 \\
CFS/ CEFS/CIFS & 18 & 4,4 \\
CAS & 5 & 1,2 \\
CFO/CHO/CEFO & 2 & 1,2 \\
CFSd/ CTSP + CFS/ CEFS/CIFS + CAS & 26 & 6,4 \\
CFSd/ CTSP + CFS/ CEFS/CIFS & 32 & 7,8 \\
CFS/ CEFS/CIFS + CAS & 2 & 0,5 \\
CFSd/ CTSP + CFO & 2 & 0,5 \\
Não respondeu & 4 & 1,0 \\
\hline
\end{tabular}

Participou de alguma disciplina/palestra que abordasse a biossegurança

\begin{tabular}{lcc} 
Sim & 298 & 72,9 \\
Não & 110 & 26,9 \\
Não respondeu & 1 & 0,2 \\
\hline Há quanto tempo foi ministrada & & \\
Há menos de 6 meses & 52 & 12,7 \\
Entre 6 meses e 1 ano & 57 & 13,9 \\
Entre 1 e 2 anos & 72 & 17,6 \\
Há mais de 2 anos & 117 & 28,6 \\
Não foi ministrada & 110 & 26,9 \\
Não respondeu & 1 & 0,2
\end{tabular}

Legenda dos Cursos*: CFSd - Curso de Formação de Soldados; CTSP - Curso Técnico em Segurança Pública; CFS - Curso de Formação de Sargentos; CEFS - Curso Especial de Formação de Sargentos; CIFS - Curso Intensivo de Formação de Sargentos; CAS - Curso de Aperfeiçoamento de Sargentos; CFO - Curso de Formação de Oficiais; $\mathrm{CHO}$ - Curso de Habilitação de Oficiais; e CEFO - Curso Especial de Formação de Oficiais para formação de oficiais. 
Além da formação do participante pela instituição nos cursos previamente citados, pré-requisito para a atuação no Corpo de Bombeiros Militar de Minas Gerais, 19,9\% informaram que cursaram ou finalizaram algum curso de graduação, tendo sido mencionados cerca de 30 cursos, dos quais os mais citados foram: Direito (12,2\%), Administração $(11,0 \%)$, Engenharia $(9,8 \%)$, Enfermagem e Educação Física $(8,5 \%)$ e Psicologia (7,3\%).

A Tabela 1 descreve alguns dos dados a respeito da formação/capacitação da amostra estudada.

Dentre os meios de atualização profissional após a formação básica, 50,2\% citaram os treinamentos institucionais; e $40,4 \%$, acesso a internet, disponível em $100 \%$ das unidades operacionais visitadas.

Ao analisar o conhecimento dos militares quanto à recomendação de higienização das mãos (HM) com água e sabão, 90,4 \% responderam corretamente que esta deve ser feita antes e depois do contato com a vítima e antes e depois de remover as luvas.

No tocante ao conhecimento da atividade antisséptica do álcool a $70 \%, 58,8 \%$ responderam equivocadamente que o álcool é utilizado devido a sua capacidade de esterilização; $18,7 \%$, também erroneamente, que sua utilização se deve à capacidade de reduzir e eliminar a matéria orgânica das mãos; e apenas $14,1 \%$ afirmaram corretamente que sua atividade deve-se à inibição do crescimento bacteriano. Ainda em relação à friç̧ão das mãos com álcool a $70 \%, 64 \%$ informaram corretamente que este produto é recomendado na ausência de sujidade visível nas mãos. Não souberam responder $22,1 \%$.

Quanto ao acondicionamento dos resíduos gerados após os atendimentos, foi relatado o uso de saco plástico branco leitoso, devidamente identificado por $82,1 \%$ dos militares.

Em relação à transmissão de doenças possivelmente adquiridas devido à natureza do trabalho no atendimento pré-hospitalar, $96,3 \%$ demonstraram conhecimento ao informar corretamente o HIV e o vírus das hepatites B e C.

Ao serem questionados quanto ao risco de desenvolver infecção após acidente com exposição da mucosa ocular do profissional, 68,6\% revelaram estar cientes de que essa infecção poderia ocorrer caso a vítima apresentasse alguma doença transmitida pelo sangue e $25,7 \%$, equivocadamente, que a infecção poderia se desenvolver se a vítima apresentasse qualquer doença, independente da forma de transmissão.

O conhecimento acerca das precauções padrão foi verificado em $89 \%$ dos socorristas, na medida em que souberam responder corretamente que elas consistiam em: utilização de equipamentos de proteção individual, como óculos, máscara, luvas, gorro, capote e sapatos imperme- áveis e fechados; lavagem das mãos; vacinação contra hepatite $B$ e descarte do material perfurocortante em recipiente de paredes rígidas.

Em relação à realização de exames sorológicos após acidente ocupacional com o envolvimento de material biológico, 68,8\%, informaram corretamente que devem ser realizados testes de HIV e de hepatites B e C no dia e três meses, seis meses e um ano depois do acidente.

O capote/avental foi o equipamento de proteção individual com maior índice de relatos, expressando dificuldade quanto à sua adesão, conforme Tabela 2.

Tabela 2 - Distribuição dos equipamentos de proteção individual quanto à dificuldade de utilização pelos bombeiros militares - Belo Horizonte, 2011

\begin{tabular}{lcc}
\hline EPI & Freqüência & Porcentagem \\
\hline Máscara facial & 46 & 11,2 \\
Óculos de segurança & 15 & 3,7 \\
\hline Capote/avental & $\mathbf{1 2 5}$ & $\mathbf{3 0 , 6}$ \\
$\begin{array}{l}\text { Luva de procedimento e capote/ } \\
\text { avental }\end{array}$ & 10 & 2,3 \\
$\begin{array}{l}\text { Máscara facial e óculos de } \\
\text { segurança }\end{array}$ & 4 & 1,0 \\
$\begin{array}{l}\text { Máscara facial e capote/avental } \\
\text { Óculos de segurança e capote/ }\end{array}$ & 24 & 5,9 \\
$\begin{array}{l}\text { avental } \\
\text { Máscara, óculos e capote/avental }\end{array}$ & 6 & 1,5 \\
$\quad$ Não respondeu & 6 & 3,4 \\
\hline Nenhuma dificuldade & $\mathbf{1 5 4}$ & $\mathbf{3 7 , 6}$ \\
\hline Total & 409 & $100 \%$ \\
\hline
\end{tabular}

Alguns participantes relataram a dificuldade de utilizar mais de um EPI. Dessa forma, eles foram agrupados na Tabela 2, a fim de reproduzir um resultado fiel à realidade encontrada.

Dentre os motivos relatados como dificultadores para a utilização do capote/avental estão: indisponibilidade na viatura, $60,5 \%$; esquecimento, $15,5 \%$; ausência de tempo, $12,3 \%$; crença de irrelevância do uso $7,8 \%$.

Embora a dificuldade de utilização de luva descartável tenha sido descrita por 10 entrevistados, $28(6,8 \%)$ informaram que o motivo da dificuldade de usá-las deve-se à indisponibilidade do tamanho apropriado da luva na viatura. De maneira semelhante, a dificuldade do uso da máscara facial foi mencionada por 91 trabalhadores e 143 apontaram os seguintes inconvenientes: embaçamento das lentes dos óculos, dificuldade de comunicação com a vítima, sensação de sufocamento, indisponibilidade na viatura, ausência de tempo, crença de irrelevância, dificuldade de utilização correta e esquecimento. Quanto aos óculos de proteção, a dificuldade de utilização esteve relacionada principalmente a: seu uso coletivo, $33,0 \%$; esquecimento $19,1 \%$; indisponibilidade na viatura $11,3 \%$; e dificuldade de avaliação da vítima 9,5\%. 


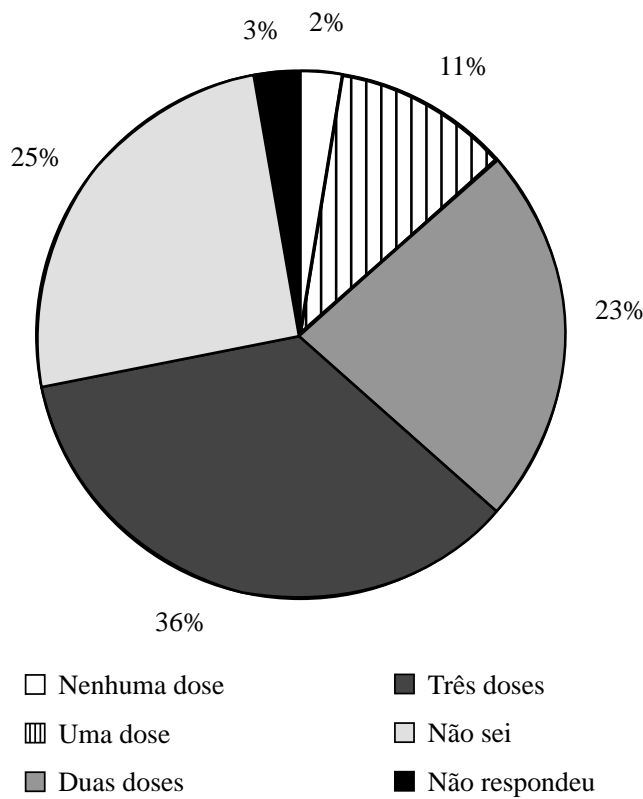

Figura 1 - Distribuição do número de doses recebidas para hepatite B Belo Horizonte, 2011.

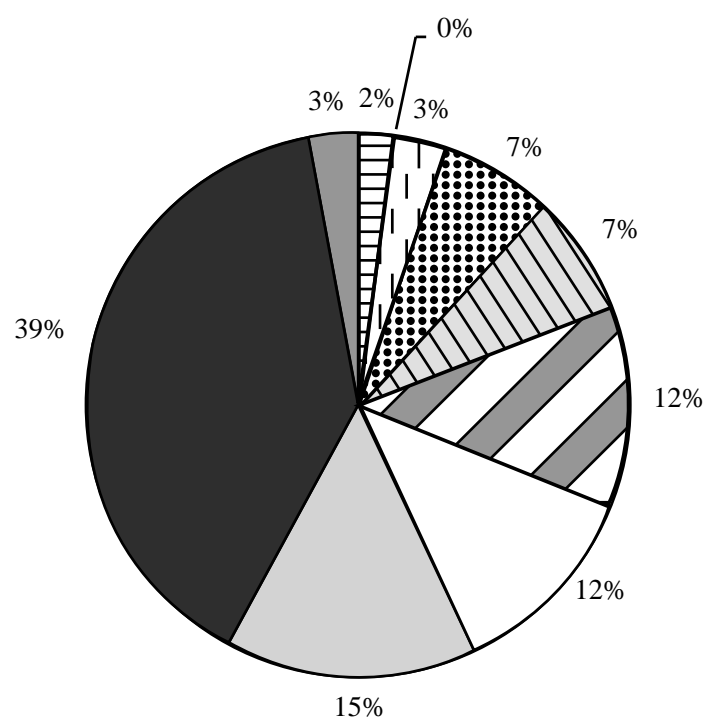

D. Água e sabão

Água e sabão, seguida de álcool a 70\%

Álcool a 70\%

Água oxigenada

Hipoclorito de sódio

$\mathbb{Q}$ Água oxigenada ou água e sabão, seguida de álcool a 70\%

围 Água oxigenada ou água e sabão, seguida de álcool a 70\% ou hipoclorito de sódio

Água oxigenada ou água e sabão ou hipoclorito de sódio

Hipoclorito de sódio ou álcool a 70\%

Figura 2 - Distribuição das soluções adotadas para limpeza de viaturas do Corpo de Bombeiros Militares no atendimento pré-hospitalar - Belo Horizonte, 2011
A diferença entre o relato de dificuldade de utilização de algum tipo de EPI e os motivos que geram essa dificuldade pode ser atribuída à sequência do questionário, que consistiu em perguntar primeiramente acerca de qual EPI o participante tinha dificuldade de usar e, em seguida, sobre o(s) motivo(s) dessa dificuldade. Logo, diante da primeira questão, muitos relataram a dificuldade de utilizar um ou outro EPI, mas, ao se deparar com a segunda, ao ler as alternativas de resposta ao(s) motivo(s) de dificuldade, lembrava-se da dificuldade de usar outro EPI que, a princípio, na primeira questão, não foi descrito como difícil de ser usado.

Para o levantamento de seu estado sorológico, os militares do Corpo de Bombeiros Militar de Minas Gerais foram questionados quanto ao número de doses recebidas para hepatite B. Constatou-se que $25,2 \%$ não sabiam o resultado de sua sorologia conforme Figura 1.

Quanto à adesão ao uso de luvas descartáveis durante procedimentos com risco de exposição a líquidos corporais da vítima, 95,7\% relataram que as usam sempre.

Ao serem questionados quanto à utilização de soluções para a limpeza das superfícies da viatura com presença de sujidade por material biológico, os seguintes produtos ou combinação destes foram relatados conforme Figura 2:

\section{DISCUSSÃO}

O predomínio do sexo masculino encontrado neste trabalho ratifica outros estudos envolvendo o atendimento pré-hospitalar em todo o Brasil ${ }^{(7-8)}$. Historicamente, o predomínio do sexo masculino entre os bombeiros militares pode ser explicado pelo fato de que os ingressantes na carreira militar deveriam ser homens hígidos, para melhor atender às demandas do serviço, que representavam riscos e exigiam considerável esforço físico. A admissão de mulheres militares estaduais após 1981 passou a corresponder a 20\% do efetivo recrutado. Atualmente, corresponde a $30 \%{ }^{(9)}$.

Quanto ao tempo dedicado aos estudos, apurou-se que menos de $25 \%$ dos participantes, sargentos ou oficiais, dedicaram mais de dez meses aos cursos de formação da corporação. A maioria dos ingressantes na corporação frequentou o Curso de Formação de Soldados ou o Curso Técnico em Segurança Pública, que são cursos de formação profissional mais básicos e de curta duração. Esses profissionais recém-formados possuem o posto de cabo ou soldado e constituem grande parte da força de trabalho militar. Geralmente, são jovens (média encontrada de 22 anos) que concluíram o ensino médio ou cursam concomitantemente a universidade e estão iniciando a carreira profissional com higidez e disposição para efetuarem suas tarefas adequadamente.

No tocante ao programa do curso de Técnico em Emergências Médicas ministrado em todos os cursos de formação do Corpo de Bombeiros Militar de Minas Gerais ${ }^{(10)}$, 
a menção à biossegurança encontra-se em uma ementa com a seguinte descrição:

(...) aspectos emocionais do cuidado de emergência, combate ao estresse, aborda a introdução aos questionamentos aos pacientes em ocorrências críticas, a segurança do cenário, isolamento de fluidos corporais, equipamento de proteção individual e precauções de segurança que possam assegurar o desempenho prático do socorrista.

Embora seja uma menção discreta às recomendações de biossegurança, fica evidente, diante dos resultados, que a abordagem do tema tem sido satisfatória para a formação dos militares no que se refere ao conhecimento e às atitudes desejáveis para seu nível de atuação durante a atividade desempenhada no âmbito pré-hospitalar.

Quanto à recomendação de lavar as mãos, a maioria dos entrevistados demonstrou conhecê-la, resultado este consoante com outros estudos ${ }^{(7,11)}$. De acordo com - Manual de Higiene das Mãos, na assistência à saúde da Organização Mundial da Saúde (OMS) de 2009, a higiene das mãos deve ser feita com água e sabão antes e depois do contato com o paciente e antes e depois de remover luvas estéreis e não estéreis, bem como quando visivelmente sujas, depois do uso do banheiro, antes e depois do preparo de medicações, depois do contato com material biológico ${ }^{(12)}$.

Trata-se de um procedimento simples e altamente eficaz, que tem seus aspectos emocional e psicológico fortemente relacionados, principalmente, para profissionais do atendimento pré-hospitalar. No entanto, em relação à infraestrutura das ambulâncias usadas para atendimento pré-hospitalar, contatou-se que elas não possuem condições adequadas à higienização de mãos, visto que não possuem torneiras com água ou pias. Portanto, a valorização do ato de lavar as mãos deve ser intensificada na chegada da viatura ao local de espera para novos atendimentos, denominado como prontidão de incêndio.

No que diz respeito à atividade antisséptica do álcool a $70 \%$, chama atenção a compreensão equivocada de sua finalidade, demonstrada por $77,5 \%$ dos participantes, seja por interpretação ou desconhecimento dos conceitos de esterilização, assepsia e desinfecção. De acordo com o CDC, a esterilização é um processo em que ocorre a destruição ou eliminação de todas as formas microbianas vivas, por meio de métodos físicos ou químicos, ação não realizada pelo álcool a $70 \%$. A desinfecção consiste no processo capaz de eliminar vários ou todos os micro-organismos patogênicos, exceto esporos bacterianos. É realizada no ambiente e em objetos inanimados. Assepsia da pele é o termo utilizado para designar a prevenção do contato com o micro-organismo(13).

O manual de higiene das mãos ensina que a atividade antimicrobiana do álcool advém de sua característica de desnaturação das proteínas de alguns vírus, bactérias e fungos, sendo o produto recomendado para antissepsia, não devendo ser utilizado em mãos sujas ou visivelmente contaminadas com material proteico, como sangue ${ }^{(12)}$, devido ao risco de redução da sua eficácia.

Tal como encontrado neste trabalho, observa-se com frequência na literatura o relato de uso de luvas de procedimentos durante todos os atendimentos prestados pelos profissionais da saúde. Entretanto, os demais EPI têm apresentado baixa adesão se comparados às luvas ${ }^{(14-16)}$.

Considera-se o relato de indisponibilidade de EPI um fato preocupante. Por isso, buscou-se averiguar essa afirmativa. Verificou-se que a ocorrência de indisponibilidade de EPI entre os meses de novembro e março é frequente. Assim, o socorrista encontra-se muitas vezes exposto a material biológico, sem proteção, devido às questões administrativas voltadas para a aquisição de material. Fato semelhante foi identificado em trabalho realizado com o Corpo de Bombeiros de Goiás em que $36,3 \%$ dos profissionais alegaram falta de material para proteção. Entretanto, a justificativa para a indisponibilidade foi a ausência de provisão do estoque, devido ao não cumprimento da atividade administrativa de reposição, sem menção à falta de material(14). Neste estudo, infere-se que tal fato, associado à questão financeira administrativa, pode ser minimizado com uma possível previsão/planejamento de material antes do fechamento do ano fiscal, contemplando um estoque até $\mathrm{o}$ ano financeiro subsequente. $\mathrm{O}$ acesso e a disponibilidade do EPI constituem fatores facilitadores para a adesão dos profissionais à sua utilização ${ }^{(17)}$.

Embora 68,8\% dos participantes tenham afirmado que a realização de exames sorológicos, depois do acidente ocupacional, para HIV e hepatite $\mathrm{B}$ e hepatite $\mathrm{C}$ deve ocorrer no dia, três, seis meses e um ano depois do ocorrido, tal resultado permanece aquém do ideal, na medida em que se fazem necessários o conhecimento e o acompanhamento sorológico, com intuito de iniciar medidas profiláticas capazes de reduzir ou eliminar o risco de desenvolvimento de alguma patologia ${ }^{(18)}$.

Em relação à cobertura vacinal, quando abordados sobre o número de doses de vacina, 25,2\% não conheciam seu estado sorológico, o que é motivo de grande preocupação, tendo em vista que a hepatite $B$ possui alto poder de infectividade após a exposição a material biológico: risco estimado entre 6 e 30\%, podendo atingir até 40\%, quando inexiste adoção de medidas profiláticas. Assim, quando comparada à hepatite $C$ e à Síndrome da Imunodeficiência Adquirida (SIDA), cujos riscos de contaminação após acidente percutâneo são, respectivamente, de 1,8\% (podendo variar de 1 a 10\%) e de $0,3 \%$ a 0,5\%, a hepatite $B$ possui maior chance de ser adquirida, sendo a única passível de prevenção pela imunização. A transmissão ocorre através do sangue e demais fluidos orgânicos, sendo a doença infecciosa mais comum entre profissionais da saúde do que na população geral, devido ao maior contato com material biológico em decorrência da profissão, devendo ser sua imunização uma exigência para exercício da profissão(7,18-21).
Conhecimento e adesão às recomendações de biossegurança no Corpo de Bombeiros Militar de Minas Gerais Oliveira AC, Machado BCA, Gama CS 
Quanto às viaturas, constatou-se que o método empregado para sua limpeza e desinfecção, na presença de fluidos orgânicos não apresenta padronização. Embora um grande número de participantes tenha respondido, corretamente, que realiza a limpeza do objeto/superfície com água e sabão, seguida de sua desinfecção com álcool a $70 \%$, muitos $(39 \%)$ relataram que usam apenas o desinfetante, sem a remoção prévia da matéria orgânica. Diante desse resultado, pode-se inferir que os conceitos e os métodos de limpeza e desinfecção não estão totalmente esclarecidos. De acordo com o CDC, a limpeza consiste na remoção de sujeira visível (orgânica e inorgânica) dos objetos e superfícies, podendo ser manual ou mecânica, usando água e sabão ou produtos enzimáticos. É considerada uma etapa essencial para o sucesso da desinfecção, posto que a presença de matéria orgânica e inorgânica é capaz de interferir na eficácia desse processo ${ }^{(13)}$.

\section{CONCLUSÃO}

Os profissionais do atendimento pré-hospitalar móvel do Corpo de Bombeiros, de forma global, demonstraram conhecimentos aceitáveis sobre as recomendações de biossegurança adquiridos nos cursos de formação de curta duração, cuja ementa contempla discretamente essa temática. Entretanto, alguns conteúdos precisam explorados em profundidade, visando alcançar maior adesão dos profissionais às medidas de biossegurança, como: recomendações de uso e características do álcool a $70 \%$; importância do esquema vacinal para hepatite $B$ em todas as três doses; apropriação de conceitos como assepsia, desinfecção e esterilização; e métodos de limpeza e desinfecção de viaturas na presença de material biológico.

Ressalta-se a identificação do conhecimento satisfatório dos militares quanto à recomendação de higienização das mãos com água e sabão. Contudo, a ausência de infraestrutura das ambulâncias usadas para o atendimento pré-hospitalar, sem pias e torneiras, dificulta a aplicação prática da teoria demonstrada e indica a necessidade de incentivo ao ato de lavar as mãos na chegada da viatura à prontidão de incêndio.

Dessa forma, sugere-se maior atenção à formação do profissional do Corpo de Bombeiro em sua prática como socorrista em atendimento pré-hospitalar vislumbrando a repercussão dessa formação em atitudes seguras que não representem riscos a seu desempenho cotidiano. Acrescenta-se a isso a recomendação de observância pela instituição do esquema de vacinação contra hepatite B, tétano e difteria, conforme recomendação da NR32, previamente à inserção do militar no campo de trabaIho. E, ainda, uma disponibilidade de EPI via previsão/ planejamento de material, com o intuito de manter um estoque suficiente para atender à demanda do serviço de forma ininterrupta.

\section{REFERÊNCIAS}

1. Soerensen AA, Morya TM, Soerensen R, Robazzi MLCC. Atendimento pré-hospitalar móvel: fatores de riscos ocupacionais. Rev Enferm UERJ [Internet]. 2008 [citado 2011 jan. 17];16(2):187-92. Disponível em: http://www.facenf.uerj. $\mathrm{br} / \mathrm{v} 16 \mathrm{n} 2 / \mathrm{v} 16 \mathrm{n} 2 \mathrm{a} 08 . \mathrm{pdf}$

2. Deslandes SF, Souza ER. Atendimento pré-hospitalar ao idoso vítima de violência em cinco capitais brasileiras. Ciênc Saúde Coletiva. 2010;15(6):2775-86.

3. Minayo MCS, Deslandes SF. Análise da implantação do sistema de atendimento pré-hospitalar móvel em cinco capitais brasileiras. Cad Saúde Pública. 2008;24(8):1877-86.

4. Brasil. Ministério da Saúde; Secretaria de Atenção à Saúde, Coordenação Geral de Urgência e Emergência. Política Nacional de Atenção às Urgências. Brasília; 2006.

5. Oliveira AC, Lopes ACS, Paiva MHRS. Occupational accidents due to exposure to biological material in the multidisciplinary team of the emergency service. Rev Esc Enferm USP [Internet]. 2009 [cited 2011 Jan 17];43(3):677-83. Available from: http://www.scielo.br/pdf/reeusp/v43n3/ en_a25v43n3.pdf
6. Siegel JD, Rhinehart E, Jackson M, Chiarello L; HealthCare Infection Control Practices Advisory Committee. 2007 Guideline for Isolation Precautions: preventing transmission of infectious agents in healthcare settings [Internet]. Atlanta: CDC; 2007 [cited 2011 Jan 17]. Available from: http://www. cdc.gov/hicpac/pdf/isolation/isolation2007.pdf

7. Lopes ACS, Oliveira AC, Silva JT, Paiva MHRS. Adesão às precauções padrão pela equipe do atendimento pré-hospitalar móvel de Belo Horizonte, Minas Gerais. Cad Saúde Pública. 2008;24(6):1387-96.

8. Zapparoli AS, Marziale MHP. Risco ocupacional em Unidades de Suporte Básico e Avançado de Vida em Emergências. Rev Bras Enferm. 2006;59(1):41-6.

9. Minas Gerais. Lei n. 11.099 , de 18 de maio de 1993. Dispõe sobre a criação do efetivo feminino do Corpo de Bombeiros. Diário Oficial do Estado de Minas Gerais, Belo Horizonte, 18 jun. 1993.

10. Minas Gerais. Corpo de Bombeiros Militar de Minas Gerais. Resolução n. 342, de julho de 2009. Dispõe sobre o módulo I (preparatório) lição 1.2 "O bem estar do socorrista". Belo Horizonte; 2009. 
11. Paudyal P, Simkhada P, Bruce, J. Infection control knowledge, attitude, and practice among Nepalese health care workers. Am J Infect Control. 2008;36(8):595-7.

12. World Health Organization (WHO). Guidelines on Hand Hygiene in Health Care, 2009. 270p

13. Rutala WA, Weber DJ; HealthCare Infection Control Practices Advisory Committee. Guideline for Disinfection and Sterilization in Healthcare Facilities, 2008 [Internet]. Atlanta: CDC; 2008 [cited 2011 Jan 17]. Available from: http://www.cdc.gov/hicpac/pdf/guidelines/disinfection_ nov_2008.pdf

14. Florêncio VB, Rodrigues CA, Pereira MS, Souza ACS. Adesão às precauções padrão entre os profissionais da equipe de resgate pré-hospitalar do Corpo de Bombeiros de Goiás. Goiânia. Rev Eletr Enferm [Internet]. 2003 [citado 2011 jun. 11];5(1):43-8. Disponível em: http://www.revistas.ufg.br/index.php/fen/article/view/770/1221

15. Harris SA, Nicolai LA. Occupational exposures in emergency medical service providers and knowledge of and compliance with universal precautions. Am J Infect Control. 2010;38(2):86-94.

16. Mafra DAL, Fonseca IC, Viana JX, Santana JCB, Silva MP. Percepção dos enfermeiros sobre a importância do uso dos equipamentos de proteção individual para riscos biológicos em um serviço de atendimento móvel de urgência. Mundo Saúde. 2008;32(1):31-8.
17. Neves HCC, Souza ACS, Medeiros M, Munari DB, Ribeiro LCM, Tipple AFV. Safety of nursing staff and determinants of adherence to personal protective equipment. Rev Latino Am Enferm. 2011;19(2):354-61.

18. Brasil. Ministério da Saúde; Secretaria de Políticas de Saúde, Coordenação Nacional de DST e AIDS. Manual de Condutas em Exposição Ocupacional a Material Biológico. Brasília;

19. Garcia LP, Facchini LA. Vacinação contra a hepatite B entre trabalhadores da atenção básica à saúde. Cad Saúde Pública. 2008;24(5):1130-40.

20. Gir E, Netto JC, Malaguti SE, Canini SR, Silva M, Hayashida M, et al. Accidents with biological material and immunization against hepatitis $B$ among students from the health area. Rev Latino Am Enferm. 2008;16(3):401-6.

21. Pinheiro J, Zeitoune RCG. Hepatite B: conhecimento e medidas de biossegurança e a saúde do trabalhador de enfermagem. Esc Anna Nery Rev Enferm. 2008;12(2):258-64. 


\section{ANEXO}

\section{QUESTIONÁRIO}

\section{Algumas informações}

Número:

Esta pesquisa tem por objetivo identificar os conhecimentos dos profissionais atuantes no atendimento pré-hospitalar do Corpo de Bombeiros em relação às recomendações de biossegurança.

\section{Lembre-se: 0 questionário deve ser respondido individualmente.}

Evite deixar questões em branco, pois sua participação é importante para o sucesso deste trabalho.

Agradecemos-lhe pelo seu tempo e disponibilidade em responder a esta pesquisa.

Cada questão tem apenas uma alternativa como resposta.

\section{1- Categoria profissional:}

( ) Subtenente/Sargento

( ) Cabo/Soldado

( ) Outros:

2- Sexo:

( ) Feminino

( ) Masculino

3- Data de nascimento:

4 - Idade: anos

\section{5- Possui algum curso de graduação?}

a) Sim. Se sim, qual?

b) Não

\section{6- Curso realizado no Corpo de Bombeiros:}

a) Curso de Formação de Soldados (CFSd)/Curso Técnico em Segurança Pública (CTSP): meses

b) Curso de Formação de Sargentos (CFS)/Curso Especial de Formação de Sargentos (CEFS)/Curso Intensivo de Formação de Sargentos (CIFS): anos meses

c) Curso de Aperfeiçoamento de Sargentos (CAS):__anos_meses

d)Curso de Formação de Oficiais (CFO)/Curso de Habilitação de Oficiais (CHO)/Curso Especial de Formação de Oficiais (CEFO): anos meses 
8) Durante sua formação no Corpo de Bombeiros, houve alguma disciplina/palestra específica sobre biossegurança ou segurança da vítima?
a) Sim.
b) Não.

9) Há quanto tempo essa disciplina/palestra foi ministrada?

a) Há menos de 6 meses.

b) Entre 6 meses e um ano.

c) Entre 1 ano e dois anos.

d) Há mais de dois anos.

e) Não foi ministrada.

10) Qual o meio que você mais utiliza para sua atualização profissional?

a) Revistas científicas.

b) Computador ou pesquisa em sites eletrônicos.

c) Televisão/jornais/rádio.

d) Participação em treinamentos em serviço, cursos, palestras, simpósios e outros.

e) Nenhum

f) Outro:

Responda as perguntas 11 a 18 com base no conhecimento teórico desenvolvido ao longo do seu curso/formação.

11) A higienização das mãos com água e sabão é recomendada:

a) Antes e após o contato com a vítima e antes e após remover luvas estéreis ou não-estéreis.

b) Apenas se a mão estiver suada.

c) Somente após o contato com cada vítima.

d) Não sei.

12) O uso de álcool a $70 \%$ está indicado para a friç̧ão das mãos considerando a seguinte característica abaixo descrita.

a) Capacidade de conservar as proteínas das bactérias.

b) Capacidade potencializar a eliminação de sujeira e matéria orgânica das mãos.

c) Inibição do crescimento microbiano.

d) Capacidade de esterilização das mãos.

e) Não sei. 


\section{3) A fricção das mãos com álcool $70 \%$ é recomendada em qual das situações abaixo?}
a) Na ausência de sujidade visível nas mãos.
b) Somente durante o contato com a mesma vítima.
c) Somente antes de sair da unidade para atender a ocorrência.
d) Não sei.

14) Após o contato do sangue da vítima com a mucosa ocular do profissional, este apresenta algum risco de desenvolver uma infecção?
a) Não, profissionais têm suficiente resistência orgânica.
b) Não, se o profissional for vacinado para hepatite B, C e HIV.
c) Sim, se a vítima apresentar alguma doença infecciosa transmitida pelo sangue.
d) Sim, se a vítima apresentar qualquer doença, independente da forma de transmissão.
e) Não sei.

15) Dentre as possíveis infecções que podem ser adquiridas devido à natureza do trabalho executado no Atendimento pré-hospitalar estão:
a) Febre amarela, tuberculose, dengue.
b) Hepatite B, hepatite C, AIDS.
c) Sarampo, leishmaniose, coqueluche.
d) Não sei.

\section{6) As precauções padrão (anteriormente denominadas precauções universais) consistem em:}

a) Usar equipamentos de proteção individual (óculos, máscara, luvas, gorro, capote e sapatos impermeáveis e fechados), lavar as mãos, vacinar contra hepatite B e desprezar material perfurocortante em recipiente de paredes rígidas.
b) Usar máscara facial, propés, friccionar álcool 70\% nas mãos, vacinar contra tétano.
c) Usar avental impermeável, luvas descartáveis e vacinar contra a tuberculose e sarampo.
d) Não sei.

\section{7) Quanto ao lixo produzido após o Atendimento Pré-Hospitalar deve-se:}
a) Acondicionar em saco plástico preto devidamente identificado.
b) Desprezar em saco plástico comum devidamente identificado.
c) Acondicionar em saco plástico branco leitoso devidamente identificado.
d) Não sei.

\section{8) Após um acidente de trabalho envolvendo fluídos corporais deve-se:}

a) Realizar testes sorológicos para HIV, hepatite B e hepatite C uma semana após o ocorrido, pois é o tempo correspondente ao período de incubação dos vírus citados.

b) Realizar testes sorológicos para HIV, hepatite B e hepatite C no dia do ocorrido, três, seis meses e um ano após o acidente. 
c) Não realizar nenhum procedimento, se o teste para HIV da vítima for negativo.

d) Não sei.

Responda as perguntas seguintes com base em suas atitudes no cotidiano de trabalho.

19) Dos equipamentos de proteção individual (EPI) abaixo listados, qual (is) você sente maior dificuldade de usar? Marque quantas opções necessitar

a) Luvas de procedimento.

b) Mascara facial.

c) Óculos de segurança.

d) Capote/avental.

e) Nenhum

f) Outro:

Responda as questões 20 a 23 conforme suas dificuldades apontadas na questão 19.

Caso não apresente dificuldades na utilização de EPI, continue a partir da questão 24.

20) A dificuldade de usar luvas se deve a:

a) Indisponibilidade do seu tamanho, na viatura.

b) Ausência de tempo durante $o$ atendimento.

c) Esquecimento.

d) Perda de sensibilidade das mãos.

e) Seu uso é irrelevante.

f) Outro:

21) A dificuldade de usar máscara se deve a:

a) Embaçamento das lentes dos óculos.

b) Sensação de sufocamento.

c) Dificuldade de comunicação com a vítima.

d) Indisponibilidade na viatura.

e) Ausência de tempo durante o atendimento.

f) Esquecimento.

g) Seu uso é irrelevante.

h) Outro:

22) A dificuldade de utilizar óculos se deve a:

a) Incompatibilidade com a máscara e crença de que ela é mais importante.

b) Indisponibilidade na viatura. 

c) Seu uso ser coletivo.
d) Dificuldade de avaliação da vítima.
e) Ausência de tempo durante o atendimento.
f) Esquecimento.
g) Seu uso é irrelevante.
h) Outro:

23) A dificuldade de utilizar capote/avental se deve a:
a) Esquecimento.
b) Indisponibilidade na viatura.
c) Ausência de tempo durante o atendimento.
d) Seu uso é irrelevante.
e) Outro:

24) Durante procedimentos em que haja risco de se expor a contato com líquidos corporais da vítima, com qual frequência você utiliza as luvas descartáveis?
a) Sempre.
b) Na maioria das vezes.
c) Algumas vezes.
d) Nunca.

25) Em relação à vacina para hepatite $B$, quantas doses você recebeu?
a) Nenhuma dose.
b) Uma dose.
c) Duas doses.
d) Três doses.
e) Não sei.

26) Qual é o procedimento de limpeza mais adotado por você, em caso de presença de sujidade das superfícies da viatura com materiais biológicos (sangue, saliva, sêmen, secreção vaginal ou do ânus, liquido amniótico), após o atendimento à vítima?
a) Limpeza das superfícies com água e sabão.
b) Limpeza das superfícies com água e sabão, seguida de álcool $70 \%$.
c) Limpeza das superfícies imediata com álcool $70 \%$.
d) Limpeza das superfícies com água oxigenada a $3 \%$.
e) Limpeza das superfícies com hipoclorito de sódio a $1 \%$.
f) Outro: 